\title{
Optimisation of an immunohistochemistry method for the determination of androgen receptor expression levels in circulating tumour cells
}

\author{
Jeffrey Cummings ${ }^{1 *}{ }^{*}$, Robert Sloane ${ }^{1 \dagger}$, Karen Morris ${ }^{1}$, Cong Zhou ${ }^{1}$, Matt Lancashire ${ }^{1}$, David Moore ${ }^{1}$, Tony Elliot ${ }^{2}$,
} Noel Clarke $^{3}$ and Caroline Dive ${ }^{1}$

\begin{abstract}
Background: AZD3514 inhibits and down regulates the androgen receptor (AR) and has undergone clinical trials in prostate cancer. To provide proof-of-mechanism (POM) in patients, an immunohistochemistry (IHC) method for determination of AR in circulating tumour cells (CTC) was developed and validated.

Methods: After an assessment of specificity validation focused on intra- and inter-operator reproducibility utilising a novel modification of incurred sample reanalysis (ISR). $\beta$-Content $\gamma$-confidence tolerance intervals (BCTI) and Cohen's Kappa (K) were employed in statistical analysis of results.

Results: In a first set of IHC reproducibility experiments, almost perfect agreement was recorded $(k=0.94)$ when two different operators scored CTC as overall positive or negative for AR. However, BCTI analysis identified a specific bias in scoring staining intensity, where one operator favoured moderate over strong assignments, whereas the reverse was the case with the second operator. After a period of additional training involving deployment of a panel of standardised images, a second set of validation experiments were conducted. These showed correction of the inter-operator bias by $\mathrm{BCTI}$ with $\mathrm{k}$ for scoring intensity increasing from 0.59 to 0.81 , indicative of almost perfect agreement.
\end{abstract}

Conclusions: By application of BCTI to the validation of $\mathrm{IHC}$, operator bias and therefore poor reproducibility can be identified, characterised and corrected to achieve a level of error normally associated with a quantitative biomarker assay, such as an ELISA. The methodological approach described herein can be applied to any generic IHC technique.

Keywords: AZD3514, Immunohistochemistry, Method validation, Incurred sample reanalysis, Cohen's Kappa, $\beta$-Content $\gamma$-confidence tolerance intervals

\section{Background}

The androgen receptor (AR) axis is a major effector in the development and progression of prostate cancer and an important target in the rational drug design of new anticancer agents [1]. Prior to interaction with ligand (principally $5 \alpha$-dihydrotestosterone, testosterone and androstenedione) the AR is localised in the cytoplasm bound to heat shock proteins and remains pre-dominantly inactive

\footnotetext{
*Correspondence: jcummings@picr.man.ac.uk

${ }^{\dagger}$ Equal contributors

${ }^{1}$ Clinical and Experimental Pharmacology Group, Cancer Research UK Manchester Institute, University of Manchester, Manchester Cancer Research Centre, Manchester M20 4BX, UK

Full list of author information is available at the end of the article
}

[2,3]. Upon binding of an androgen the receptor dissociates from heat shock proteins and translocates to the nucleus where it binds to androgen response elements located in the promoter and enhancer regions of target genes, resulting eventually in the formation of an active transcription complex after recruitment of co-regulatory proteins $[2,3]$.

AZD3514 [6-(4-\{4-[2-(4-acetylpiperazin-1-yl)ethoxy] phenyl\}piperidin-1-yl)-3-(trifluoromethyl)-7,8-dihydro $[1,2,4]$ triazolo[ $[4,3$-b]pyridazine] emerged as the preferred clinical candidate from an extensive programme of rational drug design aimed at identifying small molecule inhibitors of the AR $[4,5]$. The drug has been shown to work by binding to the AR with high affinity, preventing nuclear 
translocation of the protein and inhibiting liganddependent and independent transcriptional activity $[4,6]$. Unique to AZD3514 as a pharmacological modulator is its ability to down regulate the protein both in vitro and in vivo [6] and its anti-proliferative activity against Dunning $\mathrm{R} 3327 \mathrm{H}$ prostate tumours in rats correlated to a reduction in AR levels in tumour tissue [6]. Also, activity of this class of drug is significantly enhanced in animal models by castration. Therefore, AZD3514 entered phase I trials as an oral agent in patients with castration-resistant prostate cancer (CRPC) [7].

During the phase I trial of AZD3514 (EudraCT 2010020232-19, NCT01162395), detection and enumeration of circulating tumour cells (CTC) pre- and postadministration by the CellSearch System [8] was the major focus of the pharmacodynamic assessment of the drug [7]. Several previous studies have demonstrated that pre-dose CTC numbers around a cut-off value of 5 per $7.5 \mathrm{ml}$ of blood are prognostic of outcome in CRPC (where $\geq 5$ predicts for bad prognosis) [9-11]. Thus, CTC were incorporated primarily as a surrogate marker of the anti-tumour activity of AZD3514.

In the present study an immunohistochemistry (IHC) method has been developed for the determination of AR expression in CTC and subject to assay validation for potential application to the clinical evaluation of AZD3514. CTC were harvested from blood samples collected from the Astra Zeneca Sponsored Clinical Study (D1330N00013) by an approach termed Isolation by Size of Epithelial Tumour Cells (ISET), which lends itself more readily to IHC than the CellSearch System [12]. After an initial evaluation of specificity, validation studies focused on reproducibility $[13,14]$, where advanced statistical techniques, as recently applied to the validation of CTC enumeration by CellSearch, were employed in the analysis of data [15].

\section{Methods}

\section{Collection of patient samples}

Whole blood samples (minimum of $10 \mathrm{ml}$ ) were collected from 8 different patients entered into the Astra Zeneca sponsored clinical study D1330N00013: A Methodology Study to Assess the Variability of and Effect of Hormone Therapy on (i) Putative Androgen Regulated Gene Expression in Hair Samples and (ii) Circulating Tumour Cell Numbers and Androgen Receptor Expression in Patients with Prostate Cancer. The male subjects were from either Group 1 with localised prostate cancer with no hormonal treatment or Group 2 with locally advanced/metastatic prostate cancer on castration treatment and their characteristics are reported in Table 1.

Written informed consent was obtained from all subjects and the studies were ethically approved by the North West 6 Research Ethics Committee (REC) - Greater Manchester
South (Northwest Centre for Research Ethics Committees, 3rd Floor - Barlow House, 4 Minshull Street, Manchester M1 3DZ, UK) and the Declaration of Helsinki Principles was followed. The REC reference number for the study was $10 / \mathrm{H} 1013 / 13$. Specimens were obtained by venipuncture into EDTA tubes, stored at $4{ }^{\circ} \mathrm{C}$ and processed within $4 \mathrm{hr}$ by ISET as described below.

\section{Isolation by size of epithelial tumour cells}

Isolation of CTC from whole blood by the ISET technique was performed according to the manufacturer's instructions (Rarecells SAS, Paris, France; formerly Metagenex) [12]. Prior to filtration red blood cells were lysed in MetaBuffer (containing 0.8\% formaldehyde, Rarecells, 1:10 v/v). Filtration was then conducted through polycarbonate membranes containing $8 \mu \mathrm{m}$ pores utilising a 10 place vacuum system (Metablock, Rarecells). Thus, each $10 \mathrm{ml}$ sample yielded 10 individual filter spots, which were stored at $-20^{\circ} \mathrm{C}$ prior to staining for the AR by IHC.

\section{Immunohistochemistry of the androgen receptor in circulating tumour cells}

In order to determine the level of AR expression in CTC, ISET filters were analysed by IHC as briefly detailed below. Each individual ISET filter was attached by a paper clip to a glass slide for further handling. Filters were rehydrated in Tris-buffered saline (TBS). All steps were conducted at room temperature unless otherwise stated. Antigen retrieval of samples was conducted in a water bath at $99^{\circ} \mathrm{C}$ for $40 \mathrm{~min}$ in the presence of $250 \mathrm{ml}$ antigen retrieval solution (catalogue number S1699, DAKO, Cambridge, UK). Next, the filters were washed in TBS and incubated with permeabilisation buffer ( $0.2 \%$ triton in TBS) for $10 \mathrm{~min}$. Spots were then placed on a clean side and incubated with peroxidase block ( $3 \%$ hydrogen peroxidase in methanol) for $30 \mathrm{~min}$, after which they were washed in water. Spots were again transferred to a clean slide and incubated overnight with anti-androgen receptor antibody (clone AR441, DAKO at 1:400 in DAKO antibody diluent) in a humidity chamber at $4^{\circ} \mathrm{C}$. After incubation with antibody, filters were washed twice in TBS followed by a wash in water. Filters were then placed on a clean slide, AntiMouse EnVision + Dual Link System-HRP (DAKO) was added to each filter, which was then incubated for $1 \mathrm{hr}$ after which they were washed twice in TBS. Filters were stained for 10 min with DAKO Liquid DAB + Substrate Chromogen System for $10 \mathrm{~min}$ after which they were washed in water. Filters were counter stained with CytoBlue (Innovex Biosciences, Richom, CA, USA) and finally mounted using Faramount (DAKO).

Filters were scanned on the Bioview Allegro ${ }^{\mathrm{Tm}}$ Plus Scanner (Bioview, Rehovot, Israel) in brightfield mode, covering the entire area of the $0.6 \mathrm{~cm}$ diameter spot (scan area was set at $0.7 \mathrm{~cm}$ diameter). This scan area 
Table 1 Characteristics of subjects entered into the Astra Zeneca sponsored clinical study D1330N00013 whose blood samples where utilised in the present study

\begin{tabular}{llllll}
\hline Patient & Age (Median) & Performance status (Who) & Stage & Grade (Gleason) & Baseline PSA (Median, ng/ml) \\
\hline Group I & 71 & Normal-Restricted Activity & Localised & Intermediate (5-7) & 7.0 \\
Group II & 74 & Normal-Restricted Activity & Locally Advanced/ Metastatic & High (8-10) & 23.2 \\
\hline
\end{tabular}

was then presented digitally as multiple image frames, from which CTCs could be selected. The brown staining intensity representing the level of AR expression was graded by the analyst as follows: negative, $1+-$ weak, $2++-$ moderate, $3+++-$ strong.

\section{Characterisation of the specificity of the ISET/} immunohistochemistry methodology for the androgen receptor utilising cells lines treated with AZD3514

AZD3514 was received as a kind gift from Astra Zeneca (Oncology iMED, Alderley Park, Macclesfield, UK) and used as received. LNCaP and PC3 human prostate cancer cell lines were obtained from the American Type Culture Collection (ATCC, LGC Standards, Teddington, UK) and cultured according to ATCC recommendations in RPMI medium 1640 containing foetal bovine serum. Prior to drug treatment, LNCaP cells were cultured for $24 \mathrm{hr}$ in phenol-red free RPMI (Life Technologies Ltd, Paisley, UK) with $10 \%$ charcoal stripped foetal bovine serum (Life Technologies). The cells were then incubated for $24 \mathrm{hr}$ with $10 \mu \mathrm{M}$ AZD3514 in $1 \%$ DMSO vehicle or vehicle alone as a control. After drug treatment the cells were harvested. Whole blood for spiking with cell lines was donated by healthy human volunteers according to an ethically approved protocol (North West 6 Research Ethics Committee). Blood was spiked with either LNCaP cells prior to incubation with AZD3514 (positive control), LNCaP cells post drug treatment or PC3 cells as a negative control and were then processed by ISET and stained for AR by IHC, as described above.

\section{Statistical methods}

\section{Cohen's kappa coefficient (K)}

In order to evaluate the degree of inter-operator agreement in the assignment of a staining intensity to each CTC Cohen's kappa coefficient was calculated using GraphPad QuickCalcs (San Diego, CA, USA) based on formula 1 below [16].

$$
\mathrm{\kappa}=\frac{\operatorname{Pr}(a)-\operatorname{Pr}(\mathrm{e})}{1-\operatorname{Pr}(\mathrm{e})}
$$

Here, $\operatorname{Pr}(\mathrm{a})$ is the relative observed agreement among operators, and $\operatorname{Pr}(\mathrm{e})$ is the hypothetical probability of chance agreement, obtained using the observed data to calculate the probabilities of each observer randomly assigning each category.

\section{$\beta$-Content $\gamma$-confidence tolerance intervals}

Agreement in the staining intensity assigned by different operators was also calculated as a measure of incurred sample reanalysis (ISR) utilising $\beta$-content $\gamma$-confidence tolerance intervals (BCTI). This statistic yields an upper and lower interval where a specified $(\beta)$ proportion of measurements will lie with a specified $(\gamma)$ level of confidence and was calculated as previously reported [17]. In our adaptation of this methodology, where normally a single operator assays the same samples twice, data from a pair of operators who assayed the same samples a single time were substituted into the calculations, as described in full detail recently [15]. Calculation of BCTI was performed utilising MATLAB (Version R2009a, MathWorks, Natick, MA, USA) at $\beta=67 \%$ and $95 \%$ [18]. A plot of BCTI (y-axis) against IHC score (x-axis) represents a modified form of the 'accuracy profile'.

\section{Results}

Specificity of the ISET/IHC technique for the AR in CTC was investigated employing, as controls, human prostate cancer cell lines of known AR status, together with treatment of cells with AZD3514 in order to modulate the levels of the protein. The positive control AR expressing cell line was LNCaP while the negative control was PC3. AR status was confirmed in these cell lines by Western blot analysis utilising the same antibody (AR441) as that employed in the IHC method through the presence of a band at 110 $\mathrm{kDa}$ in $\mathrm{LNCaP}$ and the absence of a band in PC3 (Inset to Figure 1), in keeping with previously published studies [19]. Figure 1 illustrates the results obtained from a typical ISET/IHC experiment, where blood from healthy volunteers was spiked with either untreated LNCaP cells, PC3 cells or LNCaP cells incubated with AZD3514 at a dose shown to reduce AR protein expression in this cell line [6]. Untreated LNCaP cells - the positive control - demonstrated strong nuclear brown staining for (translocated) AR, whereas the PC3 cells - the negative control - displayed a complete absence of brown staining. The almost complete absence of cytoplasmic staining in $\mathrm{LNCaP}$ cells may be due to constitutive autocrine stimulation of the AR signaling pathway [20]. In addition, in LNCaP cells pretreated with AZD3514 prior to spiking into blood there was a marked reduction in the level of nuclear staining. These data indicate that the ISET/IHC method described herein can distinguish between AR positive and AR negative cancer cells in the blood of human subjects and is also 


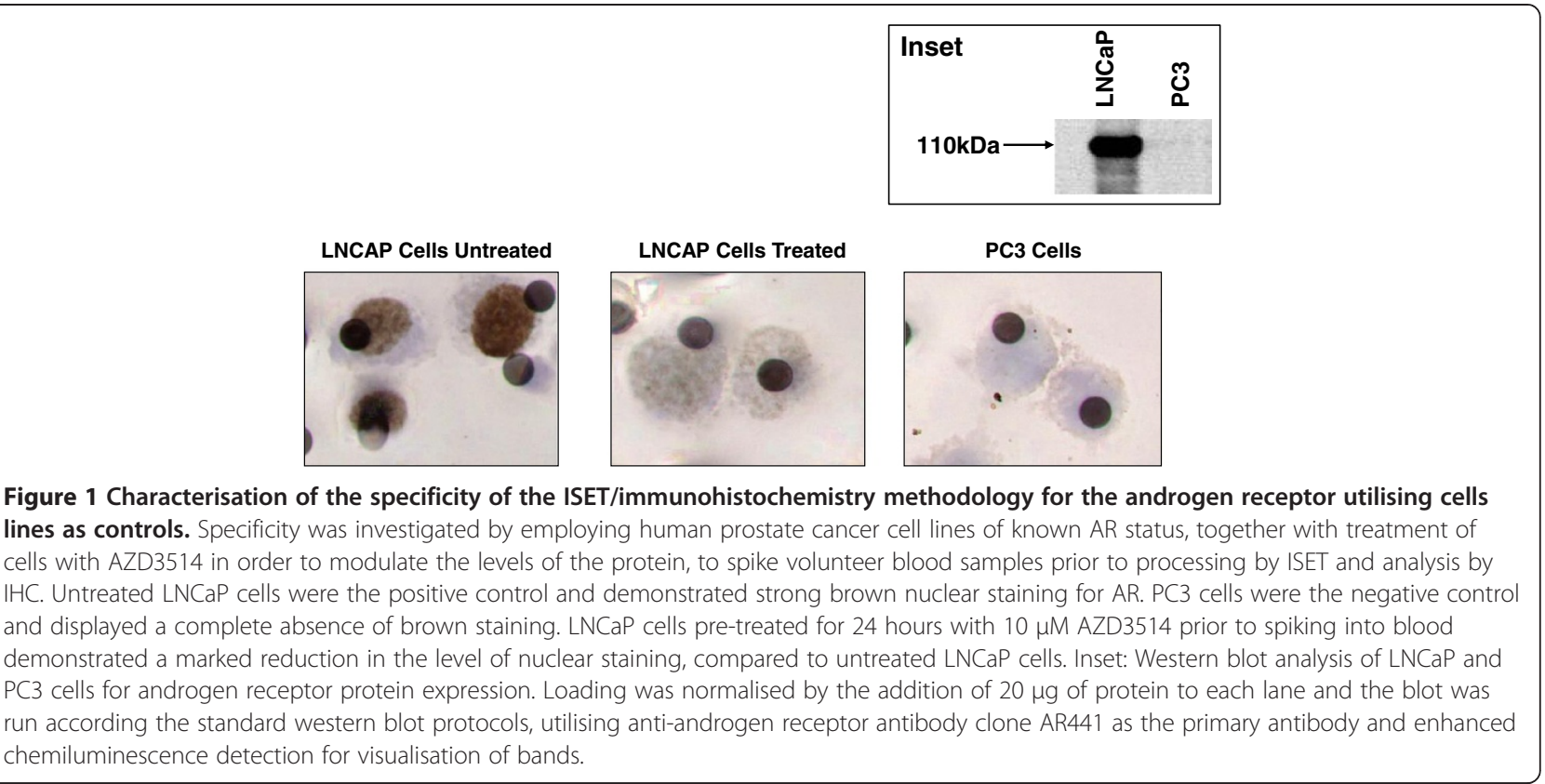

sufficiently sensitive to detect a drug induced (pharmacodynamic) knockdown in protein levels.

The major focus of the present study was to characterise between-operator and within-operator variability, employing multiple blood samples collected from either different patients or at different time points in the same patient. The number of CTCs captured in the different ISET filter spots ranged from 0 to 30 per $\mathrm{ml}$ of blood, within the range of CTC previously reported in prostate cancer patients [21].

In the first validation experiment 4 spots from 8 different patient blood samples were stained by IHC for AR expression and presented blindly to two different operators to both enumerate the CTC and score the staining intensity of each cell. The degree of inter-operator agreement was assessed both as a percentage and as $\mathrm{K}$ and is presented in Table 2. Although Cohen's kappa coefficient is a statistical measure of inter-operator agreement for qualitative (categorical) items the $\mathrm{K}$ statistic is not a test of significance. Nonetheless, it is a robust measure since it takes into account random agreement occurring by chance. Guidelines have been published to aid in the interpretation of $\kappa$ [22], and these have been previously applied to the enumeration of CTC by CellSearch [23]. Significantly, almost perfect agreement was observed when the two different operators scored CTC as overall positive or negative for AR, with a $\mathrm{k}$ value of 0.94 . However, when the scores produced by different operators for staining intensity were analysed there was a large reduction in $\mathrm{K}$ from 0.94 to 0.59 , indicating a significant degree of disagreement.

$\beta$-Content $\gamma$-confidence tolerance intervals (BCTI) reports on ISR both in the form of precision/imprecision and trueness/bias. Figure 2 illustrates the accuracy profiles at both $67 \%$ and $95 \%$ probability for the staining intensity assignments of two operators. These demonstrate a relatively large degree of imprecision, as might be expected with categorical data. However, they also highlight a significant bias, where operator 1 favoured a score of $2++$ (moderate staining intensity) over $3+++$ (strong), whereas operator 2 favoured $3+++$ over $2++$. Such a bias would not be evident by $\mathrm{k}$ alone.

After the first validation experiment a programme of staff training was embarked upon. A gallery of 20 IHC images of CTC harvested by ISET from a number of different patients was constructed in order to facilitate a supervised training workshop. Here analysts were presented with 5 different sets of images where each set included an example of a patient CTC expressing AR at weak, moderate, strong and negative staining levels. One such set of 4 graded images taken from the gallery is

Table 2 Degree of inter-operator agreement in scoring of CTC for expression of the androgen receptor by immunohistochemistry

\begin{tabular}{lllll}
\hline & $\mathbf{1}^{\text {st }}$ Run & \multicolumn{2}{l}{$\mathbf{2}^{\text {nd }}$ Run } \\
\hline Evaluation & Kappa $^{1}$ & \% Agreement & Kappa & \% Agreement \\
Positive v Negative $^{2}$ & 0.94 & 97.2 & 0.98 & 98.9 \\
Staining intensity $^{3}$ & 0.59 & 75.0 & 0.81 & 87.9
\end{tabular}

${ }^{1}$ Kappa values where calculated as described in Methods where the agreement between operators is defined as follows: $<0$ none, $0-0.20$ slight, $0.21-0.40$ fair, $0.41-0.60$ moderate, $0.61-0.80$ substantial, and $0.81-1$ almost perfect [22].

${ }^{2}$ This table entry refers to an overall assessment of the level of positive versus negative staining regardless of the staining intensity.

${ }^{3}$ Staining intensity was graded into 4 categories as negative, weak $(1+)$, moderate $(2++)$ or strong $(3+++)$. 


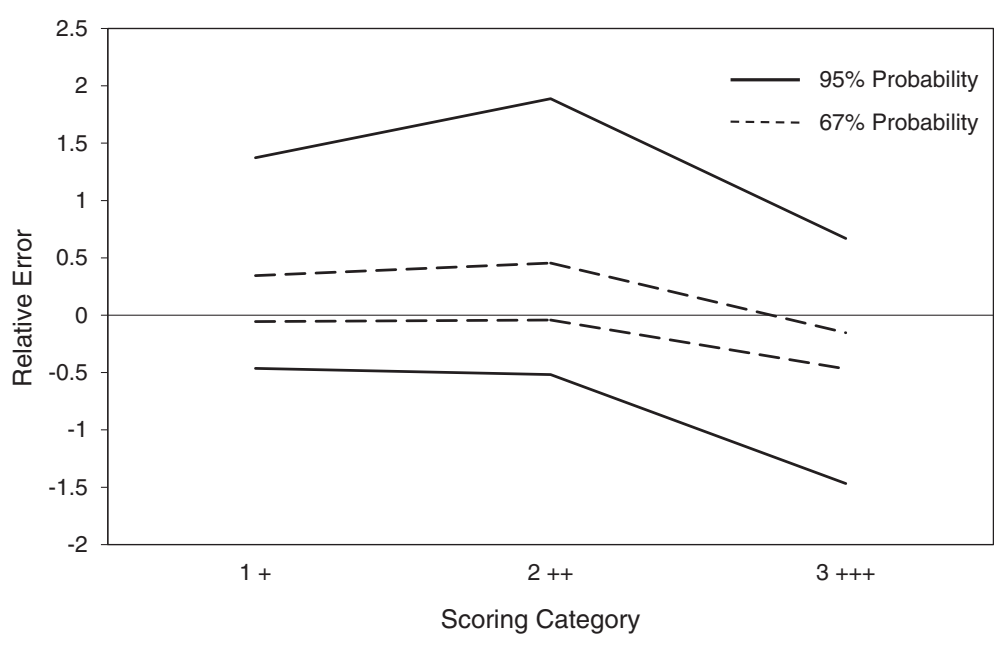

Figure 2 Characterisation of inter-operator variability in AR staining intensity by IHC in CTC harvested from patient samples by ISET. ISET membrane spots obtained after filtration of a number of different patient blood samples were stained by IHC for AR expression and presented blindly to two different analysts to both enumerate the CTC and score the staining intensity. Results were then analysed by a modification of ISR where the staining intensities obtained by each operator were substituted into the calculations. $\beta$-Content $\gamma$-confidence tolerance intervals $( \pm$ ) were calculated at $\beta=95 \%$ and $67 \%$ and the resulting accuracy profiles plotted. These revealed a systematic bias characterised by one operator favouring a score of $2++$ over another favouring $3+++$.

illustrated in Figure 3. In the second validation experiment, the bias between operators observed in experiment 1 was completely eliminated (see Figure 4), and the value of $\mathrm{K}$ for inter-operator agreement increased from 0.59 to 0.81 (Table 1), the latter being in the category of almost perfect agreement [22].

Since the samples proffered to the analysts in the second validation experiment were identical to those proffered in the first, this allowed for a conventional assessment of ISR [17] (see Figure 5). These data highlight the effect of the training programme, where analyst 1 showed a greater difference in scoring objects as $2++$ between experiments, while analyst 2 , as anticipated, showed a greater difference in scoring objects in the $3+++$ category. It is also clear that the major effect of

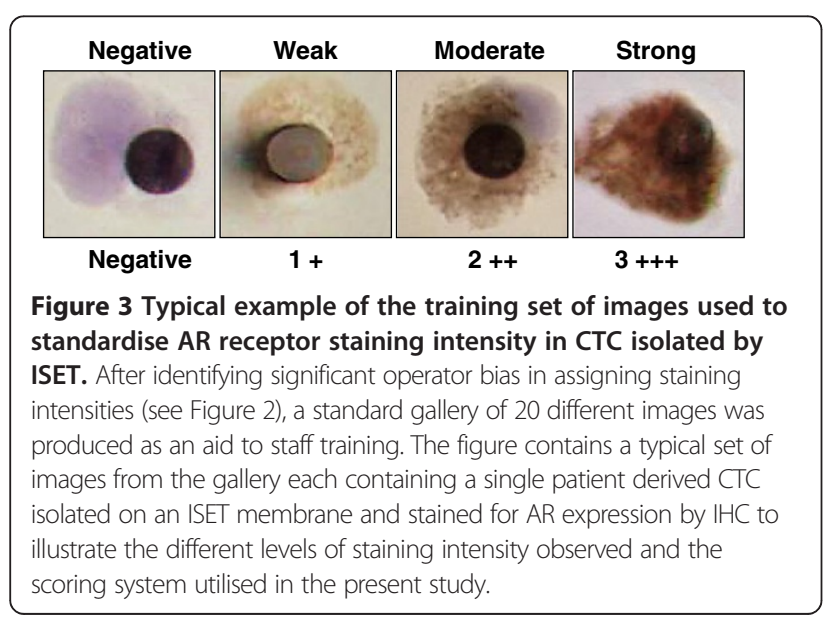

the training programme was more manifest on operator 2 , while the degree of ISR achieved by operator 1 approached $30 \%$.

\section{Discussion}

Fit-for-purpose biomarker method validation defines 5 categories of assay based on readout ranging from absolute quantitation to a nominal positive/negative result $[13,14,24,25]$. Along this spectrum, IHC in ocular microscopy mode is identified as an ordinal qualitative assay that yields categorical data presented as discrete scoring scales. Many of the performance characteristics normally associated with bioanalytical methods are not relevant to IHC, for example accuracy [26,27]. However, the main parameter of relevance to a qualitative assay is reproducibility: defined by the $\mathrm{ICH}$ as the "precision of repeated measurements between (operators and) laboratories" [14]. Or put more simply, "the property of receiving consistent results from following a specific procedure" [26]. Although there are many technical variables that could impact on the reproducibility of an IHC method, such as processing and embedding tissue and selection of section thickness, [27] the major source of error is recognised as that which is introduced by the reader $[28,29]$.

In the present paper, method validation was performed on an IHC method for the determination of AR in CTC. While the focus was obviously reproducibility in addition to an assessment of specificity, the issue of inter-operator variability was addressed in a novel manner, through a modification of ISR [30,31]. Thus, in addition to conducting ISR in the conventional format (where typically a single 


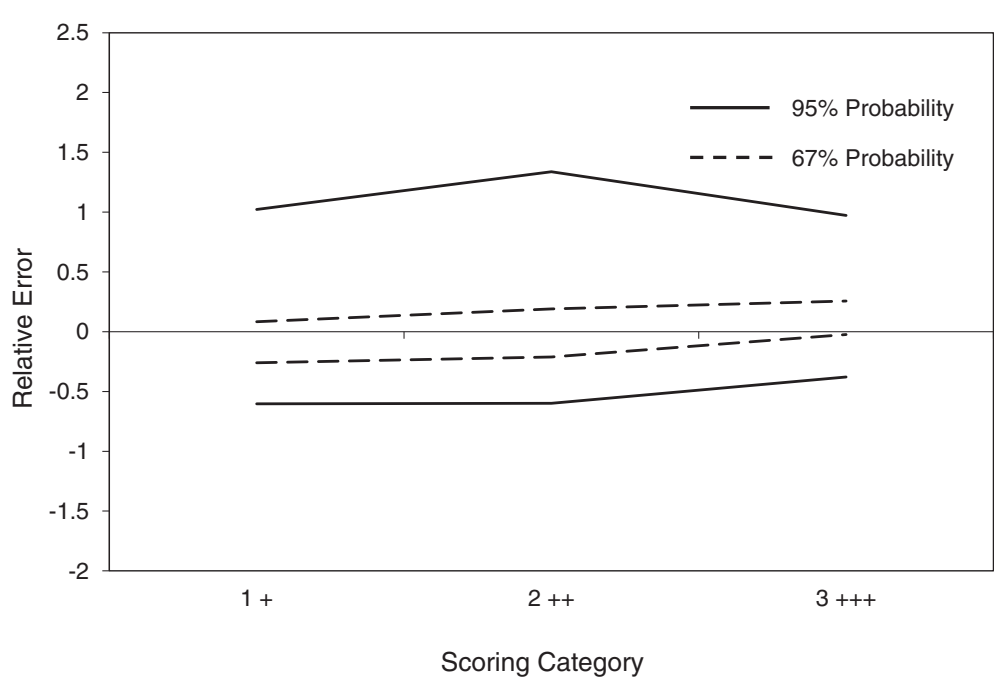

Figure 4 Further characterisation of inter-operator variability in AR staining intensity by IHC in CTC harvested from patient samples by ISET. After additional training utilising the standard gallery of images (see Figure 3), the same two analysts were invited to blindly score AR staining intensity in CTC harvested from patient blood samples by ISET. Again, results were analysed by a modification of ISR, $\beta$-content $\gamma$-confidence tolerance intervals $( \pm$ ) were calculated at $\beta=95 \%$ and $67 \%$ and the resulting accuracy profiles constructed. In this case, the bias observed in the first validation experiment (see Figure 2) appeared to be effectively eliminated.

operator analyses the same set of samples twice), in our modification two different operators each analysed the same set of samples once and the results were then subjected to statistical analysis by BCTI. We have previously demonstrated that in the case of CTC enumeration by CellSearch this modified approach to ISR was exquisitely sensitive in differentiating between both systematic (bias) and random (imprecision) errors [15]. Our results confirm that even in the relatively less complex scenario of a single CTC sitting on a filter, there is still considerable betweenoperator variability in the assignment of a scoring intensity. However, since BCTI identifies the nature of the interoperator error, it also allowed for its correction through additional staff training. In addition, by adoption of this approach it has been demonstrated that a highly trained analyst is capable of achieving scores in the repeat analysis of

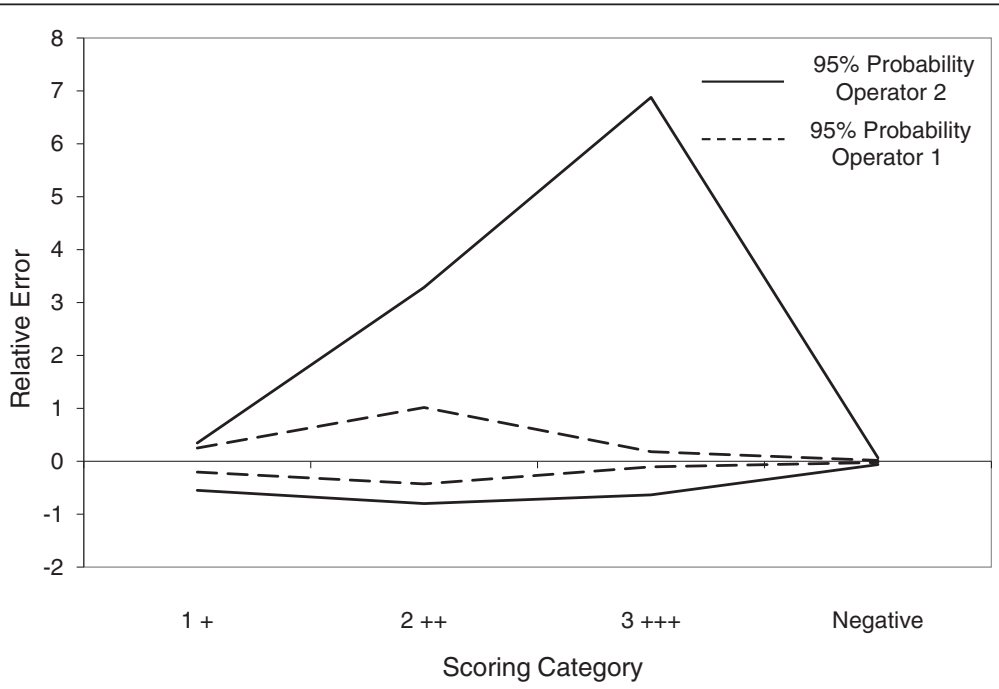

Figure 5 Incurred sample reanalysis in AR staining intensity determined by $\beta$-content $\boldsymbol{\gamma}$-confidence tolerance intervals. Due to the fact that the set of samples analysed blindly by two different operators in the first (Figure 2) and second (Figure 4) validation experiments were identical, this also allowed a conventional analysis of results by ISR utilising $\beta$-content $\gamma$-confidence tolerance intervals $( \pm)$ at $\beta=95 \%$. The resulting accuracy profiles clearly demonstrated that the training programme impacted almost exclusively on operator 2, correcting the between-operator bias in the process (Figure 2). They also highlight that the degree of ISR achievable in this analysis by operator 1 approached 30\%, which is the accepted benchmark for total error for a typical quantitative biomarker assay. 
samples that varied by $30 \%$, which is within the accepted benchmark for total error of a typical quantitative biomarker/pharmacodynamic assay such as an ELISA $[14,25,32]$.

As a categorical assay, IHC has a dynamic range restricted to a limited number (normally 3 to 4 ) of band widths of staining intensity. Nonetheless, in preclinical studies with AZD3514, and utilising the same scoring structure as the present method $(0+, 1+, 2+$ and $3+)$, IHC was able to demonstrate a dose dependent reduction on AR in tumour tissue, at doses of drug that produced only a modest inhibition of tumour growth [6]. In the same report a comparative evaluation was conducted between ocular microscopy and image analysis using the Aperio system (ePathology Solutions, Oxford, UK). Reassuringly, both approaches reported a similar level of knockdown in AR. Among current IHC techniques approved by the FDA as diagnostic, prognostic or predicative biomarkers, no claims are made that image analysis is any more accurate than visual assessment by a trained pathologist [27].

The ISET technique is an example of a tumour-markerindependent technology based on filtration through $8 \mu \mathrm{m}$ pores, unlike the FDA cleared CellSearch System which relies critically on the presence of epithelial markers (EpCam) and antibody directed capture $[21,33]$. However, the ISET technique may have an advantage over CellSearch since it is now believed that a significant proportion of malignant CTCs lose their "epithelial markers" in preference to mesenchymal antigens, in a process known as epithelial to mesenchymal transition [34-36]. As a consequence the ISET technique invariably harvests larger populations of CTC from patient blood than the CellSearch system [37]. Nonetheless, while the ISET technique is claimed to effectively remove the majority of hematologic cells - red blood cells by lysis and peripheral blood leukocytes by filtration [12] rare hematologic cells (megakaryocytes or large monocytes) or mesenchymal (endothelial) cells may be difficult to distinguish from epithelial tumour cells by cytopathologic or immunochemical analysis [38]. Indeed, it has been demonstrated in a number of different disease types, that ISET harvests cells of a non-malignant morphology from a small but significant group of subjects that could potentially result in a false-positive diagnosis [38]. These results advise caution when relying on a single technique to isolate CTC from patients.

\section{Conclusions}

A novel procedure is presented for the fit-for-purpose evaluation of the reproducibility of an IHC method for the determination of AR receptor expression levels in CTC isolated from patients as a biomarker assay utilising a modification of ISR and BCTI for statistical analysis of results. The procedure was employed to identify and correct inter-operator bias in the assignment of a scoring intensity and poor reproducibility, resulting potentially in a reduction of measurement error to a level normally associated with a quantitative biomarker assay, such as an ELISA. The methodological approach could be applied theoretically to any generic IHC method.

\section{Abbreviations}

AR: Androgen receptor; IHC: Immunohistochemistry; CTC: Circulating tumour cells; BCTI: $\beta$-content $\gamma$-confidence tolerance intervals; K: Cohen's Kappa; CRPC: Castration-resistant prostate cancer; POM: Proof-of-mechanism; ISET: Isolation by size of epithelial tumour cells; ISR: Incurred sample reanalysis; REC: Research ethics committee.

\section{Competing interests}

The authors declare that they have no competing interests.

\section{Authors' contributions}

$J C, K M, C Z, R S$ and CD were the main authors of the manuscript. CZ developed and validated all programming code utilised in statistical analysis. JC conducted the statistical analysis and interpretation of data. RS and ML performed all the laboratory analysis of samples. NC and TE collected blood samples and clinical data from patients. All authors have read and approved the final version of the manuscript.

\section{Acknowledgements}

The present study was supported with funding from the following: Cancer Research UK (C147/A12328), the Experimental Cancer Medicine Centre Network (ECMC) and Astra Zeneca. The authors would like to extend their gratitude to the staff of the Prostate Cancer Clinic at Salford Royal NHS Foundation Trust (Stott Lane, Greater Manchester, M6 8HD) from their contribution to the present study.

\section{Author details}

${ }^{1}$ Clinical and Experimental Pharmacology Group, Cancer Research UK Manchester Institute, University of Manchester, Manchester Cancer Research Centre, Manchester M20 4BX, UK. ²Department of Clinical Oncology, Christie NHS Foundation Trust, Wilmslow Road, Manchester M20 4BX, UK. ${ }^{3}$ Urology, Christie NHS Foundation Trust, Wilmslow Road, Manchester M20 4BX, UK.

Received: 28 October 2013 Accepted: 10 March 2014

Published: 28 March 2014

\section{References}

1. Mateo J, Smith A, Ong M, de Bono JS: Novel drugs targeting the androgen receptor pathway in prostate cancer. Cancer metastasis reviews 2014. doi:10.1007/s10555-013-9472-2.

2. Taplin ME: Drug insight: role of the androgen receptor in the development and progression of prostate cancer. Nature Clin Pract Oncology 2007, 4(4):236-244.

3. Knudsen KE, Penning TM: Partners in crime: deregulation of AR activity and androgen synthesis in prostate cancer. Trends Endocrinol Metab 2010, 21(5):315-324.

4. Bradbury RH, Acton DG, Broadbent NL, Brooks AN, Carr GR, Hatter G, Hayter BR, Hill KJ, Howe NJ, Jones RD, Jude D, Lamont SG, Loddick SA, McFarland HL, Parveen Z, Rabow AA, Sharma-Singh G, Stratton NC, Thomason AG, Trueman D, Walker GE, Wells SL, Wilson J, Wood JM: Discovery of AZD3514, a smallmolecule androgen receptor downregulator for treatment of advanced prostate cancer. Bioorg Med Chem Lett 2013, 23(7):1945-1948.

5. Bradbury RH, Hales NJ, Rabow AA, Walker GE, Acton DG, Andrews DM, Ballard P, Brooks NA, Colclough N, Girdwood A, Hancox UJ, Jones O, Jude D, Loddick SA, Mortlock AA: Small-molecule androgen receptor downregulators as an approach to treatment of advanced prostate cancer. Bioorg Med Chem Lett 2011, 21(18):5442-5445.

6. Loddick SA, Ross SJ, Thomason AG, Robinson DM, Walker GE, Dunkley TP, Brave SR, Broadbent N, Stratton NC, Trueman D, Mouchet E, Shaheen FS, Jacobs VN, Cumberbatch M, Wilson J, Jones RD, Bradbury RH, Rabow A, Gaughan L, Womack C, Barry ST, Robson CN, Critchlow SE, Wedge SR, Brooks AN: AZD3514: a small molecule that modulates androgen 
receptor signaling and function in vitro and in vivo. Mol Cancer Ther 2013, 12(9):1715-1727.

7. Omlin AG, Jones RJ, van der Noll R, Graham J, Ong M, Finkelman RD, Schellens JH, Zivi A, Crespo M, Clack G, Alumkal JJ, Dymond A, Dickinson A, Ranson M, Malone M, De Bono JS, Elliott T: A first-in-human study of the oral selective androgen receptor down-regulating drug (SARD) AZD3514 in patients with castration-resistant prostate cancer (CRPC). J Clin Oncol 2013, 31(Supplement):4511.

8. Tibbe AG, de Grooth BG, Greve J, Dolan GJ, Terstappen LW: Imaging technique implemented in Cell Tracks system. Cytometry 2002, 47(4):248-255.

9. de Bono JS, Scher HI, Montgomery RB, Parker C, Miller MC, Tissing H, Doyle GV, Terstappen LW, Pienta KJ, Raghavan D: Circulating tumor cells predict survival benefit from treatment in metastatic castration-resistant prostate cancer. Clin Cancer Res 2008, 14(19):6302-6309.

10. Miller MC, Doyle GV, Terstappen LW: Significance of Circulating Tumor Cells Detected by the Cell Search System in Patients with Metastatic Breast Colorectal and Prostate Cancer. J Oncol 2010, 2010:617421.

11. Scher HI, Jia X, de Bono JS, Fleisher M, Pienta KJ, Raghavan D, Heller G: Circulating tumour cells as prognostic markers in progressive, castrationresistant prostate cancer: a reanalysis of IMMC38 trial data. Lancet Oncol 2009, 10(3):233-239.

12. Vona G, Sabile A, Louha M, Sitruk V, Romana S, Schutze K, Capron F, Franco D, Pazzagli M, Vekemans M, Lacour B, Brechot C, Paterlini-Brechot P: Isolation by size of epithelial tumor cells : a new method for the immunomorphological and molecular characterization of circulatingtumor cells. Am J Pathol 2000, 156(1):57-63.

13. Cummings J, Raynaud F, Jones L, Sugar R, Dive C: Fit-for-purpose biomarker method validation for application in clinical trials of anticancer drugs. Br J Cancer 2010, 103(9):1313-1317.

14. Cummings J, Ward TH, Greystoke A, Ranson M, Dive C: Biomarker method validation in anticancer drug development. Br J Pharmacol 2008, 153(4):646-656.

15. Cummings J, Morris K, Zhou C, Sloane R, Lancashire M, Morris D, Bramley S, Krebs M, Khoja L, Dive C: Method validation of circulating tumour cell enumeration at low cell counts. BMC Cancer 2013, 13(1):415-423.

16. Cohen J: A coefficient of agreement for nominal scales. Educ Psychol Menaurement 1960, 20(1):37-46.

17. Hoffman D: Statistical considerations for assessment of bioanalytical incurred sample reproducibility. Aaps J 2009, 11(3):570-580.

18. Cummings J, Zhou C, Dive C: Application of the beta-expectation tolerance interval to method validation of the M30 and M65 ELISA cell death biomarker assays. J Chromatogr B Analyt Technol Biomed Life Sci 2011, 879(13-14):887-893.

19. Tai S, Sun Y, Squires JM, Zhang H, Oh WK, Liang CZ, Huang J: PC3 is a cell line characteristic of prostatic small cell carcinoma. The Prostate 2011, 71(15):1668-1679.

20. Gnanapragasam VJ, McCahy PJ, Neal DE, Robson CN: Insulin-like growth factor II and androgen receptor expression in the prostate. $B J U$ international 2000, 86(6):731-735.

21. Allard WJ, Matera J, Miller MC, Repollet M, Connelly MC, Rao C, Tibbe AG, Uhr JW, Terstappen LW: Tumor cells circulate in the peripheral blood of all major carcinomas but not in healthy subjects or patients with nonmalignant diseases. Clin Cancer Res 2004, 10(20):6897-6904.

22. Landis JR, Koch GG: The measurement of observer agreement for categorical data. Biometrics 1977, 33(1):159-174.

23. Kraan J, Sleijfer $S$, Strijbos MH, Ignatiadis M, Peeters D, Pierga JY, Farace F, Riethdorf S, Fehm T, Zorzino L, Tibbe AG, Maestro M, Gisbert-Criado R, Denton G, de Bono JS, Dive C, Foekens JA, Gratama JW: External quality assurance of circulating tumor cell enumeration using the Cell Search ((R)) system: a feasibility study. Cytometry B Clin Cytom 2011, 80(2):112-118.

24. Cummings J, Ward TH, Dive C: Fit-for-purpose biomarker method validation in anticancer drug development. Drug Discov Today 2010, 15(19-20):816-825.

25. Lee JW, Devanarayan V, Barrett YC, Weiner R, Allinson J, Fountain S, Keller S, Weinryb I, Green M, Duan L, Rogers JA, Millham R, O'Brien PJ, Sailstad J, Khan M, Ray C, Wagner JA: Fit-for-purpose method development and validation for successful biomarker measurement. Pharm Res 2006, 23(2):312-328.

26. Jennings L, Van Deerlin VM, Gulley ML: Recommended principles and practices for validating clinical molecular pathology tests. Arch Pathol Lab Med 2009, 133(5):743-755.
27. Dunstan RW, Wharton KA Jr, Quigley C, Lowe A: The use of immunohistochemistry for biomarker assessment-can it compete with other technologies? Toxicol Pathol 2011, 39(6):988-1002.

28. Fandel TM, Pfnur M, Schafer SC, Bacchetti P, Mast FW, Corinth C, Ansorge M, Melchior SW, Thuroff JW, Kirkpatrick CJ, Lehr HA: Do we truly see what we think we see? The role of cognitive bias in pathological interpretation. J Pathol 2008, 216(2):193-200.

29. Hamilton PW, van Diest PJ, Williams R, Gallagher AG: Do we see what we think we see? The complexities of morphological assessment. J Pathol 2009, 218(3):285-291.

30. Fast DM, Kelley M, Viswanathan CT, O'Shaughnessy J, King SP, Chaudhary A, Weiner R, DeStefano AJ, Tang D: Workshop report and follow-up-AAPS Workshop on current topics in GLP bioanalysis: Assay reproducibility for incurred samples-implications of Crystal City recommendations. Aaps J 2009, 11(2):238-241.

31. Viswanathan CT, Bansal S, Booth B, Destefano AJ, Rose MJ, Sailstad J, Shah VP, Skelly JP, Swann PG, Weiner R: Quantitative Bioanalytical Methods Validation and Implementation: Best Practices for Chromatographic and Ligand Binding Assays. Pharm Res 2007, 24(10):1962-1973.

32. Miller KJ, Bowsher RR, Celniker A, Gibbons J, Gupta S, Lee JW, Swanson SJ, Smith WC, Weiner RS: Workshop on bioanalytical methods validation for macromolecules: summary report. Pharm Res 2001, 18(9):1373-1383.

33. Tibbe AG, Miller MC, Terstappen LW: Statistical considerations for enumeration of circulating tumor cells. Cytometry A 2007, 71(3):154-162.

34. Lecharpentier A, Vielh P, Perez-Moreno P, Planchard D, Soria JC, Farace F: Detection of circulating tumour cells with a hybrid (epithelial/mesenchymal) phenotype in patients with metastatic non-small cell lung cancer. $\mathrm{Br} J$ Cancer 2011, 105(9):1338-1341.

35. Ma YC, Wang L, Yu FL: Recent Advances and Prospects in the Isolation by Size of Epithelial Tumor Cells (ISET) Methodology. Technol Cancer Res Treat 2013, 12(4):295-309.

36. Weinberg RA: Twisted epithelial-mesenchymal transition blocks senescence. Nature Cell Biology 2008, 10(9):1021-1023.

37. Khoja L, Backen A, Sloane R, Menasce L, Ryder D, Krebs M, Board R, Clack G, Hughes A, Blackhall F, Valle JW, Dive C: A pilot study to explore circulating tumour cells in pancreatic cancer as a novel biomarker. Br J Cancer 2012, 106(3):508-516.

38. Hofman VJ, Ilie MI, Bonnetaud C, Selva E, Long E, Molina T, Vignaud JM, Flejou JF, Lantuejoul S, Piaton E, Butori C, Mourad N, Poudenx M, Bahadoran P, Sibon S, Guevara N, Santini J, Venissac N, Mouroux J, Vielh P, Hofman PM: Cytopathologic detection of circulating tumor cells using the isolation by size of epithelial tumor cell method: promises and pitfalls. Am J Clin Pathol 2011, 135(1):146-156.

doi:10.1186/1471-2407-14-226

Cite this article as: Cummings et al:: Optimisation of an

immunohistochemistry method for the determination of androgen receptor expression levels in circulating tumour cells. BMC Cancer 2014 14:226.

\section{Submit your next manuscript to BioMed Central and take full advantage of:}

- Convenient online submission

- Thorough peer review

- No space constraints or color figure charges

- Immediate publication on acceptance

- Inclusion in PubMed, CAS, Scopus and Google Scholar

- Research which is freely available for redistribution 